\title{
Spatial Differentiation of Prices in the Russian Pharmaceutical Market in the Covid-19 Pandemic
}

\author{
Anna Stupnikova ${ }^{1,2, *}$ \\ ${ }^{1}$ Department of Economics and Organization Management, Amur State University, Blagoveshchensk, \\ Amur Region 675028, Russia \\ ${ }^{2}$ Economic Research Institute of Far Eastern Branch of the Russian Academy of Sciences, \\ Khabarovsk, Khabarovsk Region 680042, Russia
}

\begin{abstract}
The article presents the results of a study of a pandemic on the usual differentiation of price drugs in Russia. It is determined that the pandemic led to a significant increase in consumption and values in the first months of the regime. It was found that in the context of a pandemic in $90,6 \%$ of the studied regional markets, an increase in the level of differentiation of prices for medicines compared to 2019. It was revealed that the greatest volatility of prices for medicines was observed in the St. Petersburg market. The grouping of regional markets according to the level of spatial differentiation of prices for medicines in a pandemic showed that the group with the maximum volatility of prices for medicines was formed by four regions: Saint Petersburg, the Jewish Autonomous Region, the Republic of Khakassia and the Republic of Tatarstan.
\end{abstract}

\section{Introduction}

The welfare of the state and the quality of life of its population directly depend on the level of prices for certain goods and services. Uneven spatial dynamics is an indicator of the uneven socio-economic level of regional development. An excessive increase in prices in a particular region can provoke social unrest, a pessimistic attitude of the population after a decrease in the quality of life, migration outflows and other negative consequences.

The low level of spatial differentiation of prices in regional markets is an indicator of the high integration of the national market. Spatial market integration ensures efficient allocation of scarce resources and highly competitive markets. In an integrated market, when a supply shortage and unmet demand arises in any of its segments, the situation stabilizes as a result of arbitration activities of suppliers from other regions of the country. The transfer of excess supply to other market segments prevents the weakening of incentives for economic growth [1-4].

Most often, the level of spatial price differentiation in the country increases under the influence of price shocks caused by administrative restrictions, both internal and external, as well as natural disasters $[5,6]$.

\footnotetext{
*Corresponding author: stupnikovaann@gmail.com
} 
Thus, in an earlier study using the example of the Russian vegetable market, the author found that the introduction of the food embargo in August 2014 was followed by a powerful price shock, which led to an almost twofold increase in the average level of spatial differentiation of prices for vegetables in 2015 [7].

The epidemiological situation in the world in 2020 has become another significant factor affecting price fluctuations. The impact of the Covid-19 pandemic on the global economy peaked in the second quarter of 2020, when an unprecedented decline in global GDP and global trade was recorded.

Since March 2020, there have been two trends aimed at combating Covid-19: the removal of import restrictions and the introduction of export restrictions in a number of countries and on certain goods, including and above all on medical products and medicines. Since not all medical goods and medicines are produced within specific countries, most countries have taken measures of mutual support. Many countries have taken trade liberalization and facilitation measures to reduce the cost of imports. In particular, the European Commission issued a Decision to abolish customs duties on goods imported to contain the coronavirus.

At the same time, in a number of countries, as, for example, in many countries of Southeast Asia, export bans on medical goods were adopted. In addition, some European countries have banned the export of a number of pharmaceuticals to countries outside the European Economic Area. Restrictions were also adopted in the form of quantitative restrictions on exports or the introduction of a permitting procedure for exports (measures of licensing, control, monitoring of imports). These restrictions and prohibitions were introduced on a temporary basis as part of emergency circumstances to ensure the national security of countries, as well as in connection with the expected shortage of pharmaceuticals in the country after the outbreak of Covid-19.

As a result of the pandemic, there was a decrease in overall demand for and supply of goods and services, while there was a significant increase in demand for goods needed to combat the pandemic. In some regional markets, there was a shortage of antiviral medicines, as well as medical products used to reduce the spread of coronavirus infection. All this could have contributed to an excessive overpricing of medicines and goods in some regional markets.

The aim of this work is to identify the spatial behavior of prices for medicines in a pandemic. It is suggested that the current trends in the drug market could increase the level of spatial differentiation of prices for drugs.

\section{Trends in the Russian Pharmaceutical Market}

According to IQVIA, the share of the Russian pharmaceutical market in the global context is insignificant and varies in the range of 2-2,5\%. Russia is one of the ten largest pharmaceutical markets, but in terms of sales per capita it takes only 30 th place.

Over the past 5 years, the volume of the Russian pharmaceutical market in monetary terms has had a steady growth trend (Fig. 1). However, the market growth rates did not have unambiguous dynamics, the highest of them was typical for $2016(19,9 \%)$, the lowest for $2018(2,7 \%)$.

According to DSM Group, at the end of 2020, the volume of the Russian pharmaceutical market in value terms exceeded 2010 billion rubles, and compared to 2019 it grew by $9.8 \%$. In physical terms, the sales of drugs decreased by $4 \%$ and amounted to 6.17 billion units. The decline in drug sales in physical terms was primarily caused by a weak growth in real incomes of the population, while the cost of pharmaceutical products increased against the background of strengthening of foreign currencies against the ruble. 
It should be noted that the entire Russian pharmaceutical market is represented by two large segments: commercial and state. The public sector - the volume of the market provided with public money - hospital purchases, preferential drug provision and regional benefits - occupies 36\% of the volume of the drug market. In April 2019, the national program for the development and improvement of the Russian healthcare system "Pharma2030" was adopted. This program is primarily aimed at increasing the export of Russian medicines, increasing consumer spending on healthcare, as well as further import substitution, localization of production and the development of e-commerce in the pharmacy segment.

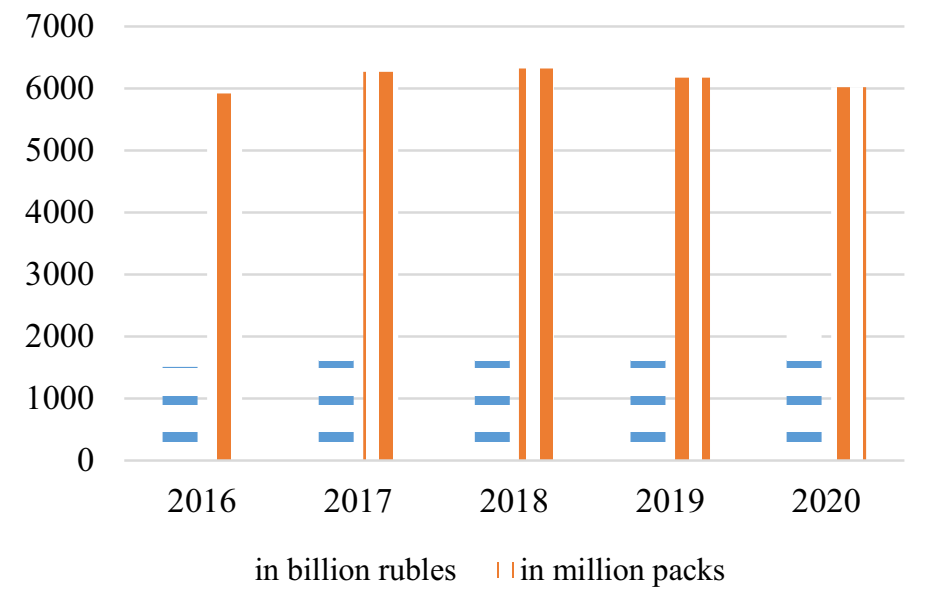

Fig. 1. Dynamics of the volume of the Russian pharmaceutical market in 2016-2020

The significant growth in the volume of the Russian pharmaceutical market in 2020 was ensured primarily by government purchases, which increased as a result of additional funding for national projects.

As for the commercial segment of the pharmaceutical market in 2017-2019. it was characterized by a decline in growth rates, which can be explained by the declining real disposable income of the population, the high cost of foreign medicines prevailing in the market. The dynamics of the commercial pharmaceutical market in 2020 was chaotic, so in March there was a rush in demand, and in the summer months, on the contrary, negative dynamics.

A specific feature of the Russian pharmaceutical market is its strong dependence on imports. On the Russian pharmaceutical market there are about 540 Russian manufacturers and 560 foreign ones, however, more foreign brands are represented in pharmacies (by 35,8 $\%)$ than Russian ones.

According to the Federal Customs Service, the main importer of medicines in the Russian Federation is Germany, which accounts for $18 \%$ of the total import of medicines. A significant share in imports (over $6 \%$ ) also belongs to Italy, France, Ireland, India. The listed countries provide almost half of all drug imports.

At the end of 2020, the share of imported drugs in the Russian pharmaceutical market as a whole amounted to $56.3 \%$ in value terms and $31.4 \%$ in physical terms. Market growth in physical terms was negative for both drugs produced in Russia $(-4 \%)$ and foreign-made drugs $(-3 \%)$. In value terms, the share of Russian drugs increased by $13 \%$, imported - by $8 \%$. The increase in the share of domestic drugs was provided primarily by Russian antiviral drugs. 
Thus, the pharmaceutical market in the context of the pandemic turned out to be one of the most vulnerable, the increased demand for drugs provoked by media reports on methods of preventing and treating a new infection, in particular for antiviral drugs and antibiotics, was not always met by supply. Also, the situation was worsened by the imposed restrictions on the export of medicines by supplier countries. Nevertheless, the unfavorable epidemiological situation, the permission of online sales of OTC drugs through online stores and government investments in the sector have given an additional impetus to the Russian pharmaceutical market.

\section{Methodology and Research Results}

A comparative analysis of the dynamics of the CPI for drugs in 2019 and 2020 made it possible to conclude that in 2020 the indicator under consideration varied more significantly (Fig. 2). Thus, the range of variation in the CPI for medicines in 2020 was 3,1 $\mathrm{pp}$, and in 2019 it was only 0,44 pp. At the same time, the maximum value of the indicator in 2020 was 2,23 percentage points higher than this indicator in 2019. In 2020, the CPI for medicines was higher compared to 2019 in March, April, and from August to December.

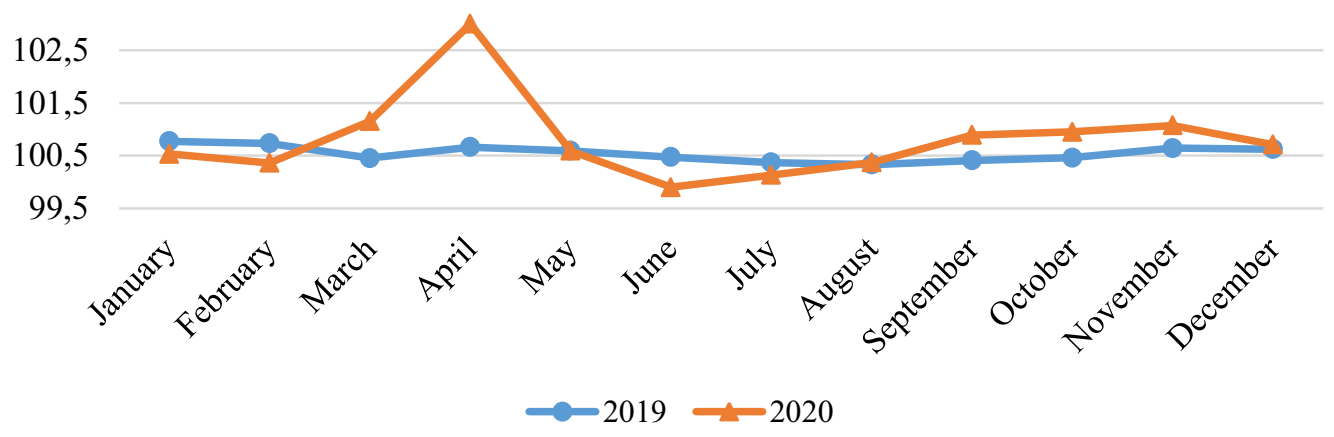

Fig. 2. Dynamics of CPI for medicines in 2019 and 2020

Comparison of the absolute deviations of the monthly CPI in 2020 with the monthly CPI in 2019 for medicines, medical services, food and all goods and services made it possible to establish the maximum values of the indicator in March and April for medicines. It should be noted that the considered indicator for food was also significant, while for medical services this indicator, on the contrary, decreased.

The theoretical and methodological basis for the study of spatial price differentiation in the Russian pharmaceutical market was the concept of spatial equilibrium of market prices.

The volatility index calculated as the standard deviation of the natural logarithms of the price data was used to assess the volatility of drug prices across regional markets. Monthly consumer price indices for medicines for 85 constituent entities of the Russian Federation for 2019 and 2020 were taken as price data.

The calculations showed that the level of drug price volatility in 2020 increased compared to 2019 by $35,7 \%$. The volatility of drug prices increased in $90,6 \%$ of the considered regional markets (Fig. 3). The maximum increase in the volatility indicator was observed in St. Petersburg, the largest decrease was recorded in the Ryazan region. 


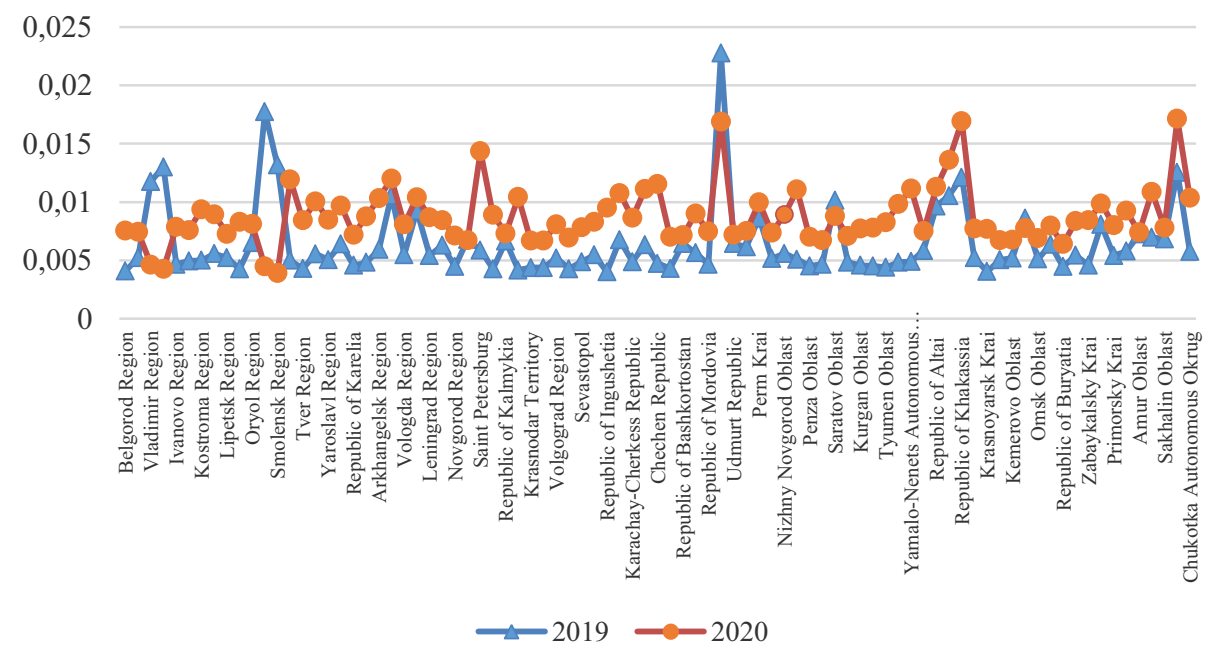

Fig. 3. Volatility of CPI for medicines in 2019 and 2020

According to the level of spatial differentiation of prices for medicines in 2020, the studied regional markets were divided into 3 groups, regions with the lowest, average and highest volatility of prices for medicines. The first group of the least volatile markets with a level of spatial differentiation of prices for medicines from 0,004 to 0,0103 included the largest number of studied regional markets - 67, including all regional markets of the Central Federal District except for the Tambov region. The second group of regional markets with a level of spatial differentiation from 0,0103 to 0,0165 included 14 regional markets. The third group of regional markets with a level of spatial differentiation of prices for medical products from 0,0165 to 0,0228 included 4 regions - St. Petersburg, the Republic of Tatarstan, the Republic of Khakassia and the Jewish Autonomous Region.

\section{Conclusion}

A comparative assessment of the volatility of the CPI for medicines in 2020 and 2019 made it possible to determine the increase in the level of spatial differentiation of prices for medicines in the context of a pandemic by $35,7 \%$. The obtained result testifies to the insufficiently high degree of integration of the Russian pharmaceutical market. In the future, in order to exclude price shocks under the influence of negative factors, including an unfavorable epidemiological situation, it is necessary to pay more attention to import substitution of drugs and the development of their domestic production, as well as the development of market infrastructure.

\section{References}

1. B.K. Goodwin, T.C. Schroeder, Cointegration Tests and Spatial Price Linkages in Regional Cattle Markets. American Journal of Agricultural Economics. Vol. 73. No. 2. Pp. 452-464 (1991)

2. M. Ravallion, Testing Market Integration. American Journal of Agricultural Economics. Vol. 68. No. 1. P. 102-109 (1986) 
3. C. Engel, J.H. Rogers, How Wide Is the Border? American Economic Review. Is. 5. P. 1112-1125 (1996)

4. P.L. Fackler, B.K. Goodwin, Spatial Price Analysis. Handbook of Agricultural Economics. Vol 1B Marketing, Distribution and Consumption. P. 971-1024 (2001)

5. B. Campenhout. Modelling Trends in Food Market Integration: Method and an Application to Tanzanian Maize Markets. Food Policy. Vol. 32. Is. 1. P. 112-127 (2007)

6. A.V. Vasilyeva. Structural Shifts in the Economy of the Amur Region. Voprosy statistiki. 26(3):23-34 (2019); (In Russ.) https://doi.org/10.34023/2313-6383-2019-263-23-34

7. A.V. Stupnikova. The Sanctions' Impact on the Integration Level of the Russian Market of Vegetables. Spatial Economics. № 3. P. 74-96 (2015) 